\title{
Crystallization Kinetics and Affecting Parameters on Polycaprolactone Composites With Inorganic and Organic Additives
}

\author{
Serap Cesur, ${ }^{1}$ Burcu Alp, ${ }^{2}$ Yelda Küçükgöksel, ${ }^{1}$ Tansel Kahraman, ${ }^{1}$ Devrim Balköse ${ }^{2}$ \\ ${ }^{1}$ Ege University, Department of Chemical Engineering, Bornova, Izmir, Turkey \\ ${ }^{2}$ Izmir Institute of Technology, Department of Chemical Engineering, Urla, Izmir, Turkey
}

\begin{abstract}
The isothermal crystallization and mechanical behavior of biodegradable polycaprolactone (PCL) composites with organic (oleic acid and glycerol monooleate) and inorganic (zinc oxide, organoclay, and hydroxy apatite) additives used alone or simultaneously were investigated. The effect of all additives on the degree of crystallinity percentage (DOC\%), isothermal crystallization kinetics parameters, and mechanical test results of PCL composites was studied. The PCL composite films were prepared by solvent casting by using dichloromethane as the solvent. The films were characterized by X-ray diffraction, differential scanning calorimetry (DSC), and tensile tests. DSC of the first melting and X-ray diffraction DOC\% results (for composites by solvent casting) are compatible. The values by DSC of the second melting (for composites by extrusion method) are lower. Organoclay gives the highest crystallinity among the other inorganic additives used. Small amounts of inorganic additives act as a nucleating agent and increase the crystallinity; the higher amounts decrease. The organic additives act as the plasticizer. When used alone, it lowers the crystallinity, but when used with inorganic additives, it improves the dispersion of inorganic particles in the polymer matrix. The isothermal crystallization kinetics parameters by Avrami analysis showed that crystallization was controlled by nucleation and the crystals had spherical structure. The nucleation type changed between thermal and athermal nucleation. The Pukanzky model interaction parameter $B$ indicated that the organic additives improved the dispersion of inorganic particles in the polymer matrix. Statistically significant, eight correlations $(F>6)$ were obtained for the crystallinity, crystallization parameters, Young's modulus, and tensile strength as a function of concentration of additives. J. VINYL ADDIT. TECHNOL., 21:174-182, 2015. (c) 2014 Society of Plastics Engineers
\end{abstract}

Correspondence to: Serap Cesur; e-mail: serap.cesur@ege.edu.tr This paper is based on the following oral presentation made in POLYSOLVAT-9, 9th International IUPAC Conference on PolymerSolvent Complexes and Intercalates, 11-14 September 2012, Kiev, Ukraine: S. Cesur, D. Balköse, B. Alp, T. Kahraman, and Y. Küçükgöksel, "Crystallization Kinetics and Affecting Parameters on PCL Composites with Inorganic and Organic Additives," Abstract in CD.

DOI 10.1002/vnl.21399

Published online in Wiley Online Library (wileyonlinelibrary.com).

(C) 2014 Society of Plastics Engineers

\section{INTRODUCTION}

Polycaprolactone (PCL) was one of the earliest polymers synthesized by the Carothers group in the early 1930s [1]. It is a biodegradable polyester produced from crude oil with a high crystallinity. Today, the importance of PCL has increased because of its degradability by microorganisms. Attention was drawn to PCL owing to its numerous advantages over other biopolymers in use at the time. These advantages included tailorable degradation kinetics and mechanical properties, ease of shaping and manufacturing with appropriate pore sizes for tissue growth, the controlled delivery of drugs contained within their matrix, and food packaging applications. Owing to the fact that PCL degrades at a slower rate than Polyglycolide and Poly(D-lactide) and its copolymers, it was therefore originally used in drug-delivery devices that remained active for over 1 year and in slowly degrading suture materials. Owing to its potential applications, it can be mixed with other polymers, for example, polystyrene [2], polyethylene [3], polypropylene [4], nano-hybrids $\mathrm{Zn} / \mathrm{Al}$-layered double hydroxide [5], hydroxy apatite (HA) [6], clay [7-9], and starch [10, 11]. For biodegradable polymeric composite applications, particles as inorganic additives in PCL have been investigated extensively. Because, oleic acid [12] and glycerol monooleate (GMO) [13] offer better interfacial properties of fluid-solid interfaces and the dispersion stability of inorganic particles in a polymer matrix, this study focused on controlling the crystallinity and mechanical behavior of PCL by using inorganic additives and organic additives simultaneously. The selected inorganic additives have crystalline structures and, when they are present in polymer solutions or in molten polymers, their crystalline surfaces act as starting points (nucleating agents) for crystallization of polymers. In other words, they act as nucleation centers. However, when they are in high concentration, they prevent the free movement of the polymer molecules and decrease the crystallinity. The isothermal crystallization kinetics and mechanical properties 
of PCL composites with zinc oxide $(\mathrm{ZnO})$, oleic acid, and GMO were reported by Alp and Cesur in a recent publication [14]. Oleic acid and GMO were miscible in PCL. They made the dispersion of $\mathrm{ZnO}$ in PCL better [14]. In the present paper, the effects of two other inorganic additives, hydroxyapatite and organo clay, which have biomedical and packaging applications, are explained in comparison. The same organic additives, oleic acid and GMO, are used for interfacial enhancement in this study.

\section{EXPERIMENTAL}

\section{Materials}

PCL (Aldrich; $\left.M_{\mathrm{n}}=70,000-90,000\right)$ and dichloromethane (Merck) were used for the preparation of the polymeric films. $\mathrm{ZnO}$ (Merck; $1-\mu \mathrm{m}$ particle size), organomodified clay (clay) (Aldrich; nanoclay, nanomer ${ }^{\circledR}$ I.34TCN, 25-30 wt\% methyl dihydroxyethyl hydrogenated tallow ammonium montmorillonite), HA (Aldrich; nanopowder, less than 200-nm particle size), oleic acid (Riedel), and GMO (Kimsan) were used as additives for controlling the crystallization of PCL and tailoring the product properties.

\section{Preparation of Composite Films}

PCL (4.2 g) (Aldrich) was dissolved in $70 \mathrm{~cm}^{3}$ of dichloromethane at room temperature and mixed with a magnetic stirrer. The effects of the selected inorganic and organic additives on crystallization and mechanical behavior of PCL were studied by adding each one by one and as inorganic and organic pairs. Therefore, the $\mathrm{ZnO}$, organoclay, or HA $(0.1,1$, and $3 \mathrm{wt} \%)$ and oleic acid (1, 3 , and $5 \mathrm{wt} \%)$ or $\operatorname{GMO}(1,3$, and $5 \mathrm{wt} \%)$ were added to the PCL solution and mixed for an additional $2 \mathrm{~h}$. In order to obtain the composite film, $10 \mathrm{~cm}^{3}$ of the mixture was poured into a Petri dish, with a diameter of $10 \mathrm{~cm}$, and then the Petri dishes with closed lids were left for $12 \mathrm{~h}$ in a hood to evaporate the solvent from the film. The composition of all prepared 28 composite films and their codes are given in Table 1. The code (IA) represents inorganic additive, (OA) organic additive, (O) oleic acid, and (G) glycerol monooleate. The inorganic additive (IA) may be $\mathrm{ZnO}(\mathrm{Z})$, clay (C), or hydroxy apatite (HA). The number given after the IA indicates the weight percentage of inorganic additive; the number after the $\mathrm{O}$ and $\mathrm{G}$ are the weight percentage of oleic acid and glycerol monooleate, respectively.

\section{Analysis of Crystal Structure, Crystallinity, and Isothermal Crystallization Kinetics}

The crystal structure of the composite films was identified by an X-ray diffractometer (Philips Xpert-Pro) employing $\mathrm{Ni}$-filtered $\mathrm{CuK}_{\alpha}$ radiation, at a scanning rate of $6 \mathrm{~min}^{-1}$ with $2 \theta$ ranging from $5^{\circ}$ to $70^{\circ}$.

The differential scanning calorimetry (DSC) experiments were performed by using a DSC instrument (TA
TABLE 1. The sample compositions and their codes.

\begin{tabular}{|c|c|c|c|}
\hline \multirow{2}{*}{$\begin{array}{l}\text { Inorganic } \\
\text { additive (IA) } \\
\text { wt } \%\end{array}$} & \multirow{2}{*}{$\begin{array}{c}\text { Organic } \\
\text { additive }(\mathrm{OA}), \\
\text { wt } \%\end{array}$} & \multicolumn{2}{|c|}{ Types of organic additives (OA) } \\
\hline & & Oleic acid $(\mathrm{O})$ & GMO $(\mathrm{G})$ \\
\hline \multirow[t]{4}{*}{0} & 0 & \multicolumn{2}{|c|}{ PCL_IA0_OA0 } \\
\hline & 1 & PCL_IA0_O1 & PCL_IA0_G1 \\
\hline & 3 & PCL_IA0_O3 & PCL_IA0_G3 \\
\hline & 5 & PCL_IA0_O5 & PCL_IA0_G5 \\
\hline \multirow[t]{4}{*}{0.1} & 0 & \multicolumn{2}{|c|}{ PCL_IA0.1_OA0 } \\
\hline & 1 & PCL_IA0.1_O1 & PCL_IA0.1_G1 \\
\hline & 3 & PCL_IA0.1_O3 & PCL_IA0.1_G3 \\
\hline & 5 & PCL_IA0.1_O5 & PCL_IA0.1_G5 \\
\hline \multirow[t]{4}{*}{1} & 0 & \multicolumn{2}{|c|}{ PCL_IA1_OA0 } \\
\hline & 1 & PCL_IA1_O1 & PCL_IA1_G1 \\
\hline & 3 & PCL_IA1_O3 & PCL_IA1_G3 \\
\hline & 5 & PCL_IA1_O5 & PCL_IA1_G5 \\
\hline \multirow[t]{4}{*}{3} & 0 & \multicolumn{2}{|c|}{ PCL_IA3_OA0 } \\
\hline & 1 & PCL_IA3_O1 & PCL_IA3_G1 \\
\hline & 3 & PCL_IA3_O3 & PCL_IA3_G3 \\
\hline & 5 & PCL_IA3_O5 & PCL_IA3_G5 \\
\hline
\end{tabular}

Instruments Q10). The samples (6 $\mathrm{mg}$ ) were placed in a covered aluminum pan and heated in flowing nitrogen atmosphere $(40 \mathrm{~mL} / \mathrm{min})$ at a $10^{\circ} \mathrm{C} / \mathrm{min}$ rate from room temperature to $100^{\circ} \mathrm{C}$, then kept for $10 \mathrm{~min}$ to delete the thermal memory. The first melting peak was obtained at this step. After that, they were rapidly cooled to $40^{\circ} \mathrm{C}$ with liquid nitrogen $\left(50^{\circ} \mathrm{C} / \mathrm{min}\right.$ as the cooling rate) and then kept for $30 \mathrm{~min}$ to $1 \mathrm{~h}$ at that temperature to observe the isothermal crystallization. The exothermic crystallization peak was obtained. After the samples were cooled to $20^{\circ} \mathrm{C}$ at a rate of $10^{\circ} \mathrm{C} / \mathrm{min}$, they were then heated again to $100^{\circ} \mathrm{C}$ at a rate of $10^{\circ} \mathrm{C} / \mathrm{min}$. A second melting peak was obtained. A representative DSC experiment output showing the temperature program, first melting peak, crystallization peak, and the second melting peak is shown in Fig. 1.

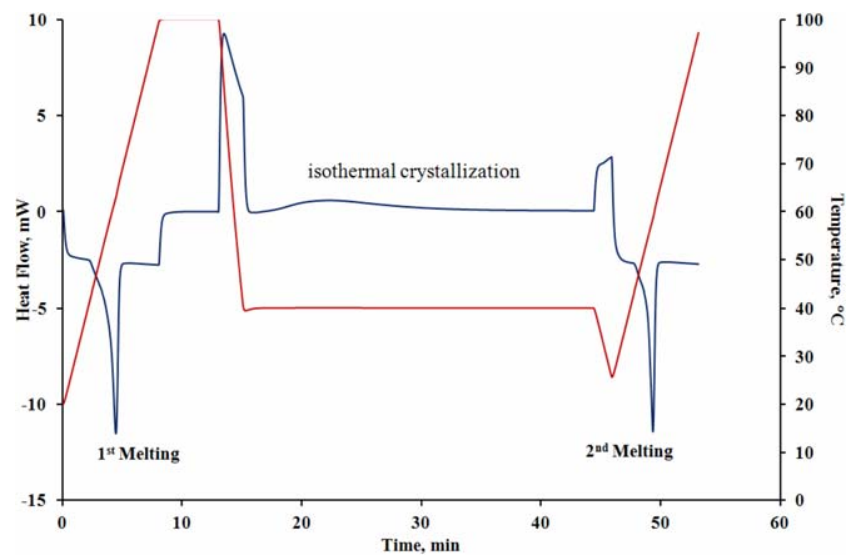

FIG. 1. DSC temperature program and DSC curve of the PCL film. Red line, temperature versus time; blue line, heat flow versus time. [Color figure can be viewed in the online issue, which is available at wileyonlinelibrary.com.] 


\section{Analysis of Mechanical Properties}

The mechanical tensile tests were done according to ASTM-D882 with a strain rate of $500 \mathrm{~mm} / \mathrm{min}$ by using a tensile test analyzer (TA-XT Plus texture analyzer). Before the tests, the samples were kept at $23 \pm 2{ }^{\circ} \mathrm{C}$ at $50 \%$ relative humidity for $48 \mathrm{~h}$.

\section{Structure and Property Correlations}

The evaluation of the results, which depends on the additive concentrations and the degree of crystallinity (DOC), was performed by using the Sigma Zone Doe Pro computer program. A multiple response regression analysis was performed, and then responses as functions of additive concentrations were examined by the surface and the Pareto of regression coefficient. A regression analysis for experiments using coded variables was done with both the linear and the quadratic effect. In the regression analysis, the $P$ value represents the importance of the effect of the variable. If the $P$ value is lower than 0.05 , the effect of the variable is highly important. The $F$ value represents the compatibility of the model with the experimental data. If the $F$ value is equal to or greater than 6 , the compatibility of the model is very good. The regression equation is as follows:

$$
Y=C_{0}+C_{1} A+C_{2} B+C_{3} A B+C_{4} A^{2}+C_{5} B^{2}
$$

where $A$ represents the wt $\%$ of the inorganic additive $(\mathrm{ZnO}$, organoclay, or HA), $B$ represents the wt $\%$ of the organic additive (oleic acid or GMO), and $Y$ represents the degree of crystallinity percent (DOC\%). For the mechanical properties, the independent variables were the wt $\%$ of inorganic fillers and the DOC\%. The most important terms effecting $Y$ were found by the Pareto analysis, and a new regression equation having only the important parameters was retested for the $F$ value higher than 6 .

\section{RESULTS AND DISCUSSION}

\section{Effect of Additives on Crystallinity}

The X-ray diffraction (XRD) diagram of the PCL film is shown in Fig. 2. The maximum peaks were observed at $2 \theta$ degrees of 21.8 and 24.08 and are caused by the 111 and 100 planes of PCL crystals in the samples. The unit cell of PCL is orthorhombic with dimensions of $a=7.496 \pm 0.002$, $b=4.974 \pm 0.001$, and $c=17.297 \pm 0.023 \AA \quad$ [15]. The orthorhombic unit cell dimensions at $31^{\circ} \mathrm{C}$ were reported as $a=7.654, b=5.024$, and $c=18.28 \AA$ by Yang and Liu [16]. The DOC\% of the composite films was calculated from the area of the crystal peaks to the total area of the peaks of the XRD pattern by using the Gaussian function.

The DOC\% of the samples from the DSC curves was determined as follows:

$$
X_{c}(\%)=\frac{\Delta H_{m}}{w \Delta H_{f}^{0}} \times 100
$$

where $\Delta H_{\mathrm{m}}$ is the melting enthalpy of the samples $(\mathrm{J} / \mathrm{g})$, $\Delta H_{f}^{0}$ is the heat of fusion of PCL at $100 \%$ crystallinity

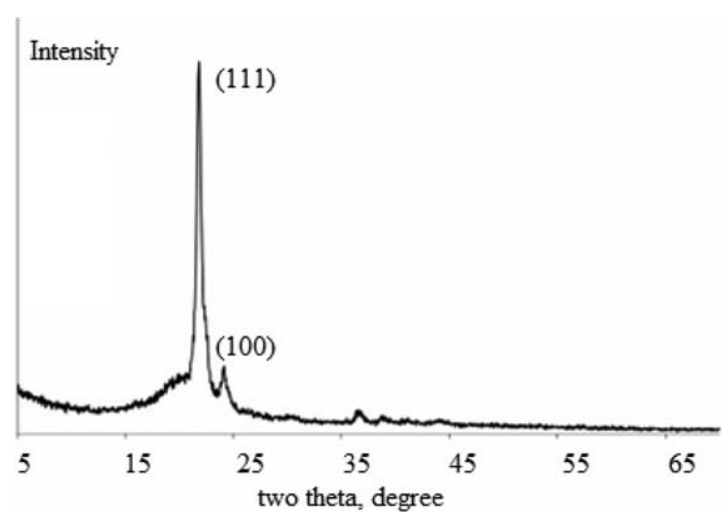

FIG. 2. XRD diagram of the PCL film.

(139.5 J/g [17]), and $w$ is the weight fraction of PCL in the film. The isothermal heating and cooling profile of the PCL film are shown in Fig. 1. The DOC\% of the samples was obtained from these two endotherms.

The DOC\% values of the composite films are given in Table 2. The lowest and the highest values of DOC\% obtained are shown as bold. The DOC values by XRD and from the area of the first melting peak in DSC analysis (Fig. 1) belong to the composites obtained by the solvent-casting method. The DOC values from the second melting peak in DSC analysis (Fig. 1) belong to the composites obtained by cooling the molten polymer as an extrusion process. The XRD results showed that the DOC, when the lowest and the highest values of $42.7 \%$ and $81.9 \%$ were ignored, changed between $45 \%$ and $65 \%$. The values by DSC of the first melting are between $42 \%$ and $64 \%$, which are comparable with XRD results. The crystallinity values of the films determined by XRD and DSC methods were close to each other but were not identical. This can be attributed to the measurement of the order of the atoms in XRD and the measurement of enthalpy changes in DSC analysis. The values by DSC peak at the second melting change between $34 \%$ and $60 \%$. The DOC values $(42 \%-64 \%)$ of composite films, which were calculated from the first melting peak, are higher than the values $(34 \%-60 \%)$ calculated from the second melting peak, owing to the different crystallization mechanisms in the solvent casting and melt crystallization processes. Although PCL molecules can freely move and pack into the crystal structure while precipitating in a solution with a low viscosity, their movement is more hindered in a melt with a high viscosity. When organic additives, oleic acid and GMO, were added at higher concentrations, lower crystallinity values were obtained, owing to the plasticizing effect of the organic additives. At a low degree of plasticization, the molecules can pack into the crystalline structure more easily. On the other hand, at a high level of plasticization, the molecules are too mobile to be fixed in a crystalline structure. For all inorganic additives used, although small amounts of inorganic additives act as a nucleating agent and increase the 
TABLE 2. Degree of crystallinity $\%$ of composite films by XRD patterns and DSC analysis.

\begin{tabular}{|c|c|c|c|c|c|c|c|c|c|c|c|}
\hline \multirow[b]{4}{*}{ Inorganic additive, wt $\%$} & & & \multicolumn{9}{|c|}{ Degree of crystallinity $\%$} \\
\hline & \multirow{2}{*}{\multicolumn{2}{|c|}{$\begin{array}{l}\text { Organic } \\
\text { additive }\end{array}$}} & \multirow{2}{*}{\multicolumn{3}{|c|}{ XRD }} & \multicolumn{6}{|c|}{$\mathrm{DSC}$} \\
\hline & & & & & & \multicolumn{3}{|c|}{ 1st melting } & \multicolumn{3}{|c|}{ 2nd melting } \\
\hline & wt $\%$ & Type & $\mathrm{ZnO}$ & Clay & HA & $\mathrm{ZnO}$ & Clay & HA & $\mathrm{ZnO}$ & Clay & HA \\
\hline \multirow[t]{8}{*}{0} & 0 & $\mathrm{OA}$ & & 58.82 & & & 57.81 & & & 42.85 & \\
\hline & 1 & & & 57.14 & & & 63.12 & & & 46.66 & \\
\hline & 3 & & & 53.31 & & & 64.49 & & & 47.31 & \\
\hline & 5 & & & 47.99 & & & 62.82 & & & 45.04 & \\
\hline & 0 & GMO & & 58.82 & & & 57.81 & & & 42.85 & \\
\hline & 1 & & & 53.00 & & & 45.65 & & & 38.43 & \\
\hline & 3 & & & 53.00 & & & 46.00 & & & 36.60 & \\
\hline & 5 & & & 51.00 & & & 43.37 & & & 34.33 & \\
\hline \multirow[t]{8}{*}{0.1} & 0 & $\mathrm{OA}$ & 45.81 & 47.76 & 60.08 & 55.23 & 57.25 & 49.97 & 37.52 & 42.70 & 35.71 \\
\hline & 1 & & 44.86 & 81.90 & 56.57 & 59.15 & 64.09 & 53.82 & 42.57 & 60.03 & 38.48 \\
\hline & 3 & & 48.16 & 47.26 & 57.56 & 58.17 & 53.38 & 50.35 & 42.68 & 44.51 & 37.72 \\
\hline & 5 & & 42.66 & 49.01 & 56.62 & 57.09 & 52.51 & 48.08 & 41.24 & 42.77 & 36.79 \\
\hline & 0 & GMO & 45.81 & 47.76 & 60.08 & 55.23 & 57.25 & 49.97 & 37.52 & 42.70 & 35.71 \\
\hline & 1 & & 50.70 & 45.09 & 56.28 & 53.23 & 60.06 & 53.55 & 41.16 & 42.18 & 39.13 \\
\hline & 3 & & 55.00 & 46.89 & 57.14 & 54.30 & 59.40 & 53.94 & 36.88 & 41.46 & 38.45 \\
\hline & 5 & & 53.00 & 47.38 & 56.03 & 44.70 & 57.57 & 47.95 & 36.20 & 40.68 & 35.16 \\
\hline \multirow[t]{8}{*}{1} & 0 & $\mathrm{OA}$ & 54.20 & 50.20 & 55.40 & 59.00 & 56.40 & 51.60 & 41.50 & 41.50 & 38.80 \\
\hline & 1 & & 62.20 & 52.70 & 56.80 & 54.40 & 58.70 & 52.30 & 39.20 & 40.20 & 38.70 \\
\hline & 3 & & 55.40 & 47.30 & 60.60 & 57.00 & 58.30 & 50.40 & 42.30 & 39.00 & 36.90 \\
\hline & 5 & & 53.70 & 46.90 & 65.20 & 61.00 & 52.50 & 46.10 & 44.50 & 37.00 & 34.80 \\
\hline & 0 & GMO & 54.20 & 50.20 & 55.40 & 59.00 & 56.40 & 51.60 & 41.50 & 41.50 & 38.80 \\
\hline & 1 & & 53.00 & 43.30 & 56.90 & 47.80 & 55.90 & 49.70 & 38.60 & 41.30 & 36.80 \\
\hline & 3 & & 49.00 & 47.20 & 59.40 & 45.40 & 54.40 & 49.20 & 37.30 & 42.70 & 37.10 \\
\hline & 5 & & 47.00 & 46.30 & 63.50 & 46.10 & 51.20 & 46.60 & 35.50 & 37.70 & 33.70 \\
\hline \multirow[t]{8}{*}{3} & 0 & $\mathrm{OA}$ & 50.20 & 48.50 & 63.50 & 51.90 & 54.70 & 50.10 & 37.10 & 40.30 & 36.50 \\
\hline & 1 & & 48.40 & 46.60 & 56.00 & 55.70 & 56.80 & 48.40 & 56.30 & 55.20 & 49.40 \\
\hline & 3 & & 45.40 & 45.70 & 53.60 & 45.60 & 55.90 & 46.10 & 50.30 & 53.20 & 50.60 \\
\hline & 5 & & 47.20 & 43.80 & 52.90 & 42.20 & 51.70 & 46.10 & 46.90 & 54.6 & 50.20 \\
\hline & 0 & GMO & 50.20 & 48.50 & 63.50 & 51.90 & 54.70 & 50.10 & 37.10 & 40.30 & 36.50 \\
\hline & 1 & & 53.00 & 42.90 & 56.70 & 48.50 & 54.20 & 54.50 & 53.90 & 58.30 & 58.40 \\
\hline & 3 & & 51.00 & 48.60 & 53.50 & 48.10 & 51.50 & 54.30 & 50.10 & 58.20 & 56.10 \\
\hline & 5 & & 50.00 & 47.40 & 52.30 & 41.60 & 49.50 & 53.40 & 57.20 & 55.40 & 52.50 \\
\hline
\end{tabular}

crystallinity, the higher amount makes them lower. Similar observations were reported when clay was used [18-20]. The DSC crystallinity of solvent-cast PCL films without any additive is $57.81 \%$. The crystallinity values of the films change with the addition of $\mathrm{ZnO}$, clay, and hydroxyapatite alone or simultaneously with oleic acid or GMO in the range of 41.6-61.0\%, 49.5$64.1 \%, 46.1-53.8 \%$, respectively. The crystallinity of the melt crystallized neat PCL film is $42.8 \%$. It changes with the addition of $\mathrm{ZnO}$, clay, and hydroxyapatite alone or simultaneously with oleic acid or GMO in the range of $35.5-57.2 \%, 37.0-60.3 \%$, and $33.7-$ $58.4 \%$, respectively. The minimum crystallinity values for oleic acid and GMO added films are 42.8 and $34.3 \%$, respectively. However, the maximum values are $46.7 \%$ and $42.8 \%$ for oleic acid and GMO, respectively. GMO lowers the crystallinity. Thus, it was possible to change the crystallinity of PCL by adding organic additives alone, inorganic additives alone, or simultaneously as well as heat treatment. Thus, it is possible to obtain composites with desired crystallinity values depending on the application field.

\section{Crystallization Kinetics by Avrami Analysis}

The crystallization kinetic parameters were obtained from the isothermal crystallization peak area at $40^{\circ} \mathrm{C}$ using the Avrami model. The Avrami model [21] was used to analyze the crystallization rates of the samples, as given in Eq. 3:

$$
X_{t}=1-\exp \left(-k t^{n}\right)
$$

where $X_{\mathrm{t}}$ is the relative crystallinity, $n$ is the Avrami constant, which depends on the mechanism of nucleation and the crystal growth, $t$ is the real time of crystallization, and $k$ is the crystallization rate constant involving both nucleation and growth rate parameters. The relative crystallinity can be defined as a function of time in the following form from DSC peak of crystallization: 
TABLE 3. The crystallization kinetics parameters of the film samples by the Avrami model.

\begin{tabular}{|c|c|c|c|c|c|c|c|c|c|c|c|}
\hline \multirow[b]{2}{*}{ Inorganic additive wt $\%$} & \multicolumn{2}{|c|}{ Organic additive } & \multicolumn{3}{|c|}{$t_{1 / 2}, \min$} & \multicolumn{3}{|c|}{$n$} & \multicolumn{3}{|c|}{$\mathrm{k} \times 10^{3}, \min ^{-1}$} \\
\hline & $\mathrm{wt} \%$ & Type & $\mathrm{ZnO}$ & Clay & HA & $\mathrm{ZnO}$ & Clay & HA & $\mathrm{ZnO}$ & Clay & HA \\
\hline \multirow[t]{8}{*}{0} & 0 & OA & & 7.13 & & & 2.05 & & & 12.4 & \\
\hline & 1 & & & 4.68 & & & 1.86 & & & 39.3 & \\
\hline & 3 & & & 6.83 & & & 1.86 & & & 19.4 & \\
\hline & 5 & & & 5.25 & & & 2.01 & & & 24.7 & \\
\hline & 0 & GMO & & 7.13 & & & 2.05 & & & 12.4 & \\
\hline & 1 & & & 10.27 & & & 2.37 & & & 2.8 & \\
\hline & 3 & & & 10.63 & & & 2.05 & & & 5.5 & \\
\hline & 5 & & & 10.93 & & & 2.05 & & & 5.1 & \\
\hline \multirow[t]{8}{*}{0.1} & 0 & $\mathrm{OA}$ & 6.41 & 8.67 & 9.27 & 2.32 & 2.21 & 2.06 & 9.3 & 5.9 & 7 \\
\hline & 1 & & 5.08 & 10.58 & 11.63 & 2.42 & 1.86 & 2.19 & 13.6 & 39.3 & 3.2 \\
\hline & 3 & & 5 & 8.85 & 10.44 & 2.27 & 2.13 & 2.19 & 18 & 6.7 & 4.1 \\
\hline & 5 & & 7.23 & 8.39 & 9.33 & 2.53 & 2.33 & 2.06 & 4.6 & 4.9 & 7 \\
\hline & 0 & GMO & 6.41 & 8.67 & 9.27 & 2.32 & 2.21 & 2.06 & 9.3 & 5.9 & 7 \\
\hline & 1 & & 10.47 & 7.99 & 12.21 & 2.02 & 2.37 & 1.36 & 6 & 2.8 & 23 \\
\hline & 3 & & 11.5 & 12.48 & 10.11 & 2.17 & 2.26 & 2.12 & 3.5 & 2.3 & 5.1 \\
\hline & 5 & & 12.04 & 10.37 & 10.5 & 2.1 & 2.35 & 2.09 & 3.7 & 2.8 & 5 \\
\hline \multirow[t]{8}{*}{1} & 0 & OA & 4.01 & 7.67 & 8.92 & 2.73 & 2.66 & 1.87 & 15.6 & 3.1 & 11.7 \\
\hline & 1 & & 4.96 & 7.1 & 8.23 & 2.36 & 2.31 & 1.95 & 15.8 & 7.5 & 11.3 \\
\hline & 3 & & 3.68 & 6.37 & 8.71 & 2.52 & 2.58 & 2.26 & 26 & 5.8 & 5.2 \\
\hline & 5 & & 9.33 & 8.6 & 9.25 & 2.16 & 2.46 & 1.99 & 5.6 & 3.5 & 8.3 \\
\hline & 0 & GMO & 4.01 & 7.67 & 8.92 & 2.73 & 2.66 & 1.87 & 15.6 & 3.1 & 11.7 \\
\hline & 1 & & 7.46 & 10.59 & 12.71 & 2.7 & 2.34 & 1.3 & 3.1 & 2.8 & 25.4 \\
\hline & 3 & & 9.64 & 7.97 & 13.06 & 2.33 & 2.53 & 1.22 & 3.5 & 3.6 & 30.3 \\
\hline & 5 & & 11.61 & 11.94 & 10.31 & 2.16 & 2.12 & 2.23 & 3.5 & 3.6 & 3.8 \\
\hline \multirow[t]{8}{*}{3} & 0 & OA & 3.95 & 8.49 & 11.09 & 2.5 & 2.39 & 2.26 & 22.4 & 4.2 & 3 \\
\hline & 1 & & 7.71 & 8.16 & 12.97 & 2.56 & 2.29 & 1.37 & 3.7 & 5.7 & 20.8 \\
\hline & 3 & & 10.08 & 7.41 & 10.45 & 2.77 & 2.45 & 2.04 & 1.2 & 5.8 & 5.7 \\
\hline & 5 & & 4.81 & 8.25 & 10.71 & 2.67 & 2.48 & 2.09 & 10.4 & 3.7 & 4.9 \\
\hline & 0 & GMO & 3.95 & 8.49 & 11.09 & 2.5 & 2.39 & 2.26 & 22.3 & 4.2 & 3 \\
\hline & 1 & & 8.45 & 9.57 & 10.84 & 2.06 & 2.38 & 2.44 & 8.5 & 3.2 & 2.1 \\
\hline & 3 & & 9.37 & 10.8 & 7.77 & 2.35 & 2.13 & 2.94 & 3.6 & 3.6 & 1.7 \\
\hline & 5 & & 8.31 & 8.29 & 9.2 & 2.57 & 2.54 & 2.37 & 3 & 3.2 & 3.6 \\
\hline
\end{tabular}

$$
X_{t}=\frac{\int_{0}^{t}\left(\frac{d H}{d t}\right) d t}{\int_{0}^{\infty}\left(\frac{d H}{d t}\right) d t}
$$

where $H$ is the crystallization enthalpy during the infinitesimal time interval at $d t$ and $\infty$ is the time at the end of crystallization.

Then, Eq. 3 can be linearized as follows:

$$
\ln \left[-\ln \left(1-X_{t}\right)\right]=\ln k+n \ln t
$$

and when plotting $\ln \left[-\ln \left(1-X_{t}\right)\right]$ vs. $\ln t$ at a given crystallization temperature, a straight line should be obtained to determine the Avrami kinetics constants. The slope of the line is equal to $n$ and the intercept is $\ln k$. Also, $k$ can be determined from the crystallization half-time, which is defined as the time taken for the crystallinity of the sample to reach the value of $50 \%$ of the relative crystallinity,

$$
k=\frac{(\ln 2)}{t_{1 / 2}^{n}}
$$

The crystallization kinetics parameters were obtained from isothermal exotherm of each composite film using the Avrami model and are summarized in Table 3. A representative DSC exotherm is shown in Fig. 1. The lowest and the highest values obtained are shown as bold in Table 3. The values of $n$ and $k$ obtained with Eq. 5 from the slope and intercept of the best fitting line with $R^{2}=0.99$ are reported in Table 3. As the linear part is considered the primary crystallization, a second nonlinear part, which deviated slightly, is considered secondary crystallization, which was caused by the growth of the spherulites. As a matter of fact, the Avrami model is valid for the linear part of these curves. The $n$ values changed between 1.22 and 2.94, which represents that the crystallization is controlled by nucleation and has spherical structure and that the nucleation type changed between the thermal and athermal nucleation process followed by three-dimensional crystal growth [22, 23]. The effect of additives on the isothermal crystallization kinetics parameter of $n$ can be seen in Fig. 3. Figure 3a shows the effect of inorganic additives; Fig. $3 b$ shows the effect of organic additives; Fig. 3c shows the effect of inorganic additives with oleic acid, and Fig. 3d shows the effect of inorganic additives with GMO. Di Maio et al. [24] reported that the isothermal crystallization of PCL/ clay nanocomposites at different clay concentrations showed that the well-dispersed organoclay platelets acted 

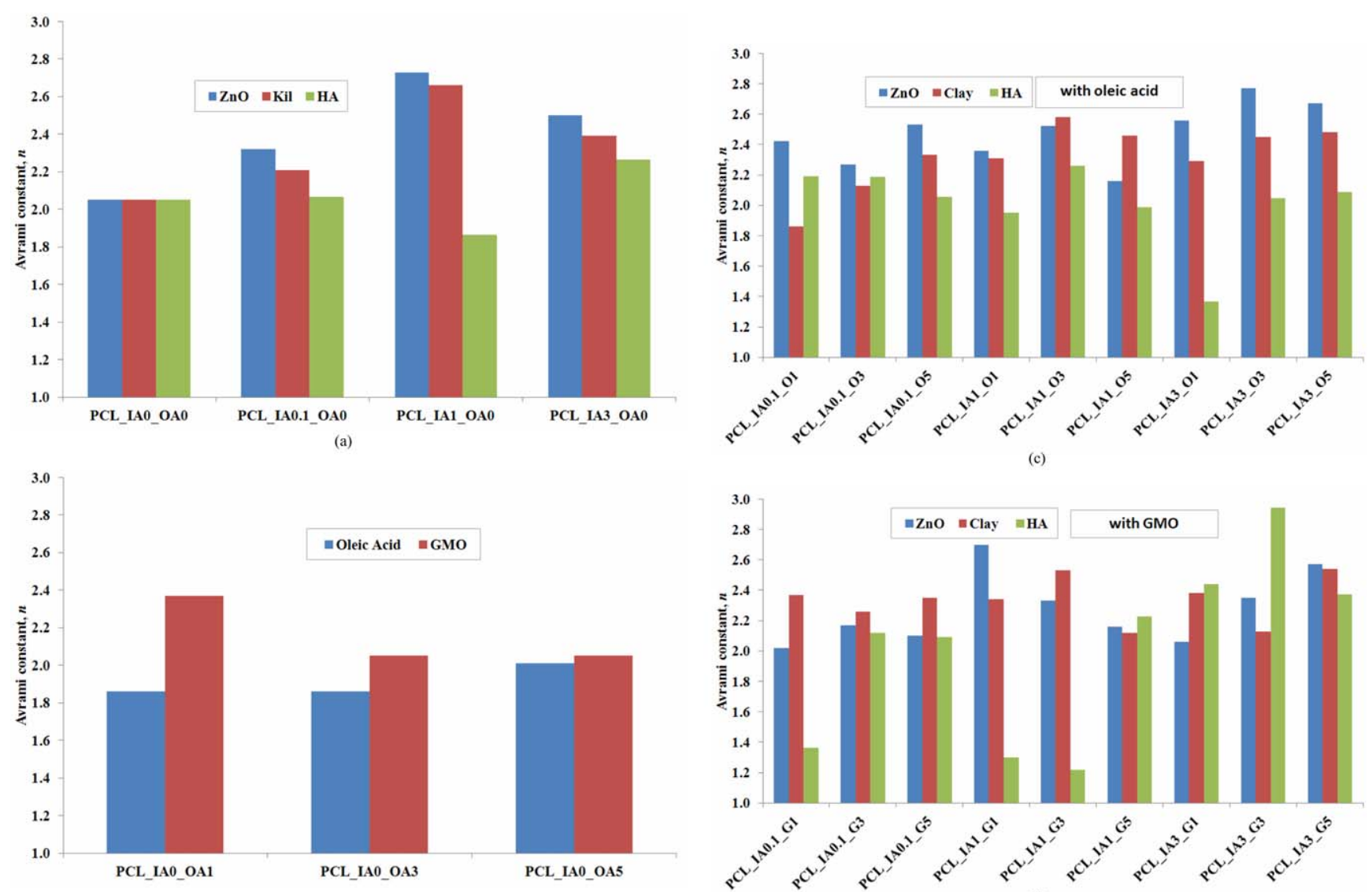

(c)

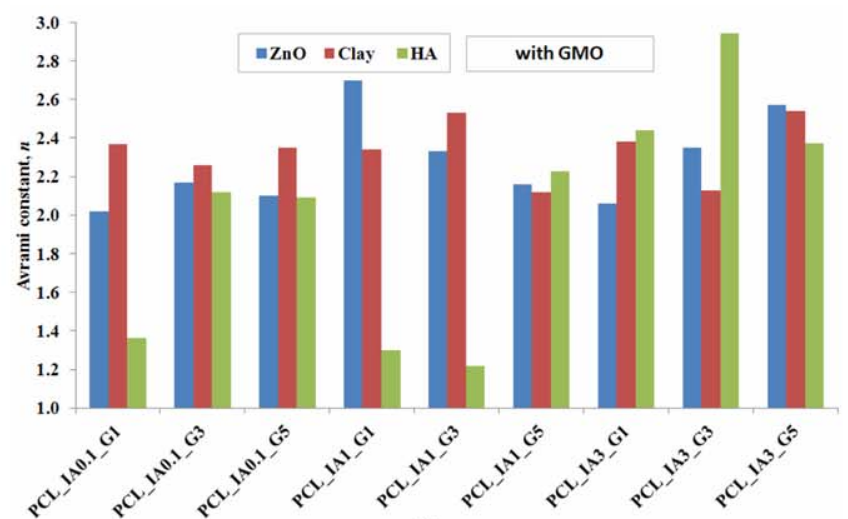

(b)

(d)

FIG. 3. Effect of additives on the isothermal crystallization kinetics parameter of $n$. (a) Inorganic additives; (b) organic additives; (c) inorganic additives with oleic acid, (d) inorganic additives with GMO. [Color figure can be viewed in the online issue, which is available at wileyonlinelibrary.com.]

as nucleating agents in the PCL matrix, remarkably reducing the crystallization half-time, $t_{1 / 2}$. In this study, the addition of an inorganic additive also decreased the crystallization half-time $t_{1 / 2}$, and, therefore, the whole crystallization time. The crystallization half-time values changed between 3.95 and 13.06 minutes. GMO slows down the crystallization by increasing the time; it can be concluded that GMO lowers the rate of the crystallization process. The shortest time of $3.95 \mathrm{~min}$ is achieved with 3 $\mathrm{wt} \% \mathrm{ZnO}$ addition.

\section{Mechanical Properties}

The Young's modulus and tensile strength of the films are reported in Table 4 . The additives affected the mechanical properties of the samples. The Young's modulus and tensile strength of neat PCL film prepared by solvent casting were measured as $0.12 \mathrm{GPa}$ and $9.75 \mathrm{MPa}$, respectively. They are in the same order, but lower than the values reported for melt-processed PCL [18]. They increased to $0.16 \mathrm{GPa}$ and $17.8 \mathrm{MPa}$ when $1 \mathrm{wt} \% \mathrm{GMO}$ was added. It was reported that the modulus of elasticity was increased with the filler content for melt-intercalated organoclay-PCL composites [18]. The maximum Young's modulus value $(0.25 \mathrm{GPa})$ was observed for solvent-cast film with $3 \mathrm{wt} \%$
HA and $1 \mathrm{wt} \% \mathrm{OA}$ in the present study. However, the lowest Young's modulus $(0.08 \mathrm{GPa})$ was observed for $0.1 \% \mathrm{ZnO}$ and $5 \%$ (oleic acid)-added film and also for $3 \mathrm{wt} \% \mathrm{ZnO}$ and $5 \mathrm{wt} \%$ GMO-added film. The lowest tensile strength was 6.8 $\mathrm{MPa}$ for $0.1 \%$ clay and 5\% GMO-added composite. The PCL composite films were flexible films with Young's modulus between 0.08 and $0.25 \mathrm{GPa}$. Their tensile strength can be changed between 6.8 and $18.5 \mathrm{MPa}$ and it is sufficient for applications that need not carry heavy loads.

Interfacial interaction between the fillers and matrix is an important factor affecting the mechanical properties of the composites [25]. Thus, theoretical tensile yield strength and ultimate tensile strength of the composites are modeled for the cases of adhesion and no adhesion between the filler particles and matrix. The Pukanzky model describes the effects of composition and the interfacial interaction on tensile yield stress of particulatefilled polymers. The parameter $B$ is an interaction parameter that is related to the macroscopic characteristics of the filler-matrix interface and interphase:

$$
\frac{\sigma_{y c}}{\sigma_{y m}}=\frac{1-\phi_{f}}{1+2.5 \phi_{f}} \exp \left(B \phi_{f}\right)
$$

where $\phi_{\mathrm{f}}$ is a volume fraction of filler, and $\sigma_{\mathrm{yc}}$ and $\sigma_{\mathrm{ym}}$ denote the tensile yield stress of the composite and 
TABLE 4. Young's modulus and tensile strength values of composite films.

\begin{tabular}{|c|c|c|c|c|c|c|c|c|c|c|c|c|c|}
\hline \multirow{3}{*}{$\begin{array}{l}\text { Inorganic } \\
\text { additive, wt } \%\end{array}$} & \multirow{3}{*}{$\begin{array}{c}\text { Organic } \\
\text { additive, wt } \%\end{array}$} & \multicolumn{6}{|c|}{ Young's modulus, GPa } & \multicolumn{6}{|c|}{ Tensile strength, $\mathrm{MPa}$} \\
\hline & & \multicolumn{2}{|c|}{$\mathrm{ZnO}$} & \multicolumn{2}{|c|}{ Clay } & \multicolumn{2}{|c|}{ HA } & \multicolumn{2}{|c|}{$\mathrm{ZnO}$} & \multicolumn{2}{|c|}{ Kil } & \multicolumn{2}{|c|}{ HA } \\
\hline & & $\mathrm{OA}$ & GMO & $\mathrm{OA}$ & GMO & $\mathrm{OA}$ & GMO & $\mathrm{OA}$ & GMO & $\mathrm{OA}$ & GMO & $\mathrm{OA}$ & GMO \\
\hline \multirow[t]{4}{*}{0} & 0 & \multicolumn{6}{|c|}{0.12} & \multicolumn{6}{|c|}{9.75} \\
\hline & 1 & 0.1 & 0.16 & 0.1 & 0.16 & 0.1 & 0.16 & 8.55 & 17.81 & 8.55 & 17.81 & 8.55 & 17.81 \\
\hline & 3 & 0.13 & 0.12 & 0.13 & 0.12 & 0.13 & 0.12 & 13.05 & 11.87 & 13.05 & 11.87 & 13.05 & 11.87 \\
\hline & 5 & 0.1 & 0.13 & 0.1 & 0.13 & 0.1 & 0.13 & 9.4 & 14.28 & 9.4 & 14.28 & 9.4 & 14.28 \\
\hline \multirow[t]{4}{*}{0.1} & 0 & \multicolumn{2}{|c|}{0.09} & \multicolumn{2}{|c|}{0.11} & \multicolumn{2}{|c|}{0.13} & \multicolumn{2}{|c|}{8.67} & \multicolumn{2}{|c|}{9.32} & \multicolumn{2}{|c|}{8.48} \\
\hline & 1 & 0.1 & 0.12 & 0.11 & 0.1 & 0.14 & 0.14 & 8.52 & 18.46 & 9.95 & 11.03 & 9.34 & 9.05 \\
\hline & 3 & 0.1 & 0.09 & 0.11 & 0.12 & 0.13 & 0.14 & 8.38 & 15.05 & 10.99 & 11.74 & 6.9 & 9.62 \\
\hline & 5 & 0.08 & 0.12 & 0.1 & 0.11 & 0.13 & 0.14 & 7.45 & 11.68 & 8.72 & 6.82 & 9.16 & 9.62 \\
\hline \multirow[t]{4}{*}{1} & 0 & \multicolumn{2}{|c|}{0.12} & \multicolumn{2}{|c|}{0.13} & \multicolumn{2}{|c|}{0.15} & \multicolumn{2}{|c|}{8.13} & \multicolumn{2}{|c|}{9.85} & \multicolumn{2}{|c|}{9.8} \\
\hline & 1 & 0.11 & 0.14 & 0.11 & 0.11 & 0.2 & 0.14 & 9.71 & 13.63 & 9.59 & 12.46 & 11.68 & 10.82 \\
\hline & 3 & 0.11 & 0.1 & 0.11 & 0.11 & 0.17 & 0.14 & 12.94 & 11.29 & 9.49 & 10.41 & 9.94 & 9.54 \\
\hline & 5 & 0.1 & 0.09 & 0.11 & 0.12 & 0.19 & 0.14 & 10.01 & 10.23 & 11.12 & 11.97 & 12.47 & 10.5 \\
\hline \multirow[t]{4}{*}{3} & 0 & \multicolumn{2}{|c|}{0.11} & \multicolumn{2}{|c|}{0.13} & \multicolumn{2}{|c|}{0.13} & \multicolumn{2}{|c|}{9.83} & \multicolumn{2}{|c|}{9.09} & & \\
\hline & 1 & 0.09 & 0.1 & 0.11 & 0.16 & 0.25 & 0.13 & 8.19 & 10.15 & 10.05 & 10.33 & 14.73 & 8.22 \\
\hline & 3 & 0.09 & 0.09 & 0.1 & 0.13 & 0.16 & 0.13 & 9.76 & 9.31 & 10.72 & 11.83 & 8.51 & 10.31 \\
\hline & 5 & 0.1 & 0.08 & 0.12 & 0.14 & 0.2 & 0.14 & 10.16 & 7.63 & 11.7 & 11.2 & 11.99 & 9.96 \\
\hline
\end{tabular}

matrix, respectively. The first term in $E q .7$ is related to the decrease in effective load-bearing cross-section, and the second term is concerned with the interfacial interaction between filler and matrix. Interfacial interaction depends on the area of the interphase, and the strength of the interaction, as shown in Eq. 8:

$$
B=\left(1+A_{f} \rho_{f} t\right) \ln \left(\frac{\sigma_{y i}}{\sigma_{y m}}\right)
$$

where $t, \sigma_{\mathrm{yi}}, A_{\mathrm{f}}$, and $\rho_{\mathrm{f}}$ are the thickness of the interface, strength of interaction, the specific surface area, and the density of the filler, respectively.

The polymer additive interaction parameter $B$ (calculated from Eq. 8) of the PCL composite films is shown in Fig. 4. Parameter $B$ in the model characterizes the interaction between PCL and additives, and the higher $B$ values indicate the better interaction. Negative $B$ values result from weak adhesion at the interface of polymer and additive. The highest negative value of $B$ was obtained as -70.62 for a percentage of 0.1 nanoclay-doped composite without the organic additives (Fig. 4a). The addition of organic additives to this film changed the value of $B$ to positive values, for example, to $2.3 \%$ for $3 \%$ GMO addition. The organic additives made the interaction of the fillers and the PCL stronger.

\section{Statistical Analysis}

The DOC values (from DSC), Avrami kinetic parameters, Young's modulus, and tensile strength of PCL films were statistically modeled by fitting Eq. 1 as the starting trial. The effective parameters indicated by the Pareto analysis were used to find new model equations with higher $R^{2}$ and $F$ values. Statistically significant model equations could be obtained for some cases in the present study. The statistically significant eight model equations obtained with $F$ values higher than 6 are reported in Table 5. DOC\% values of $\mathrm{ZnO}-\mathrm{OA}$ and $\mathrm{ZnO}-\mathrm{GMO}$ composites can be predicted with the correlations obtained. Crystallization half-time can also be predicted for $\mathrm{ZnO}$ GMO composites. The effect of DOC\% and the additives on mechanical properties can be predicted.

It can be concluded that the weight percentage of organic and inorganic additives have an effect on the crystallinity and crystallization kinetics parameters on the PCL composites. For the mechanical properties of the composites, not only the concentration of additives, but also the crystallinity of the samples was found to be effective.

\section{CONCLUSION}

This study focused on the crystallization control of biodegradable PCL. When organic additives, OA and GMO, were added at higher concentrations, lower crystallinity values were obtained. This could be owing to the plasticizing effect of the organic additives. The DOC (XRD) decreased in the presence of an increasing amount of organic additives; oleic acid caused decrements in the DOC in the presence of inorganic additives in comparison with GMO. For all inorganic additives used, although small amounts of inorganic additives acted as a nucleating agent and increased the crystallinity, the higher amount lowered. The DSC crystallinity of solvent-cast PCL films without any additive is $57.81 \%$. The crystallinity values of the films changed with the addition of $\mathrm{ZnO}$, clay, and hydroxyapatite alone or simultaneously with oleic acid or GMO in the range of $41.6-61.0 \%, 49.5-64.1 \%$, and $46.1-$ $53.8 \%$, respectively. The crystallinity of the meltcrystallized neat PCL film is $42.8 \%$. It changes with the 


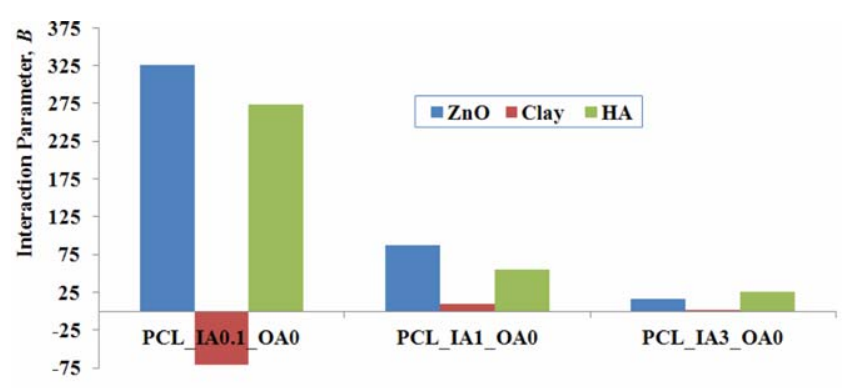

(a)

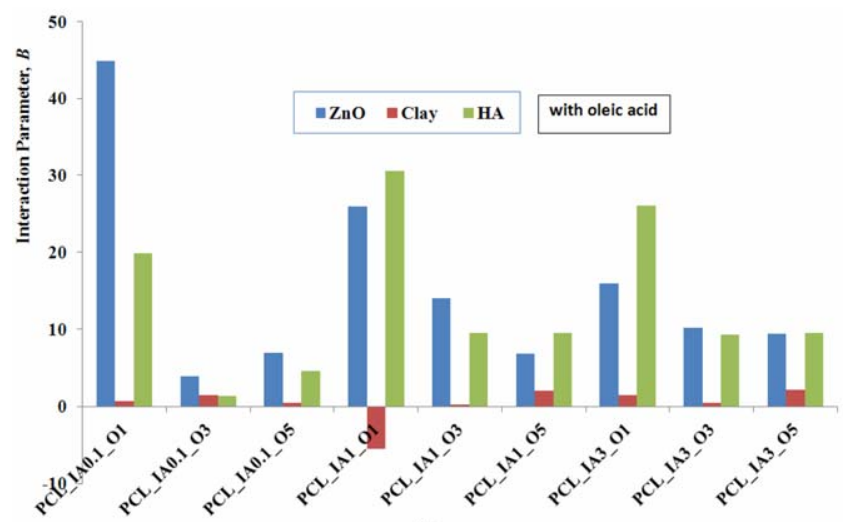

(b)

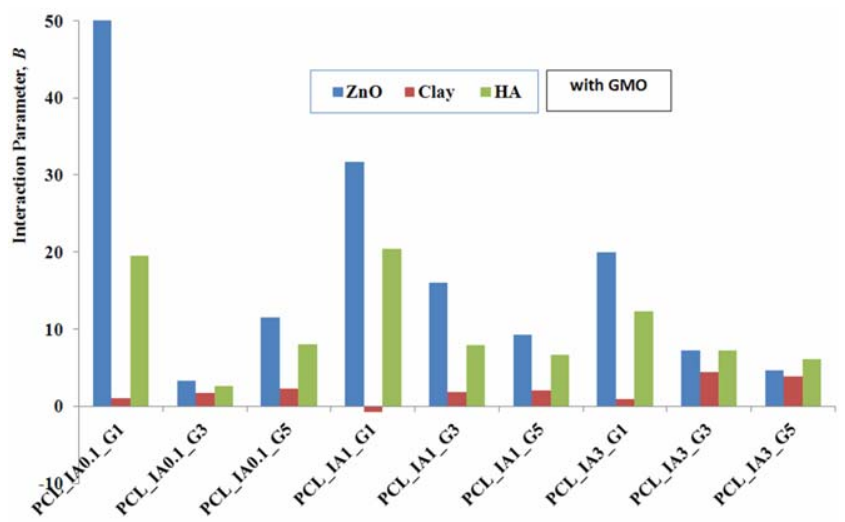

(c)

FIG. 4. The polymer additive interaction parameter $B$ values calculated from the Pukanszky model of the PCL films. (a) Effect of inorganic additives; (b) effect of inorganic additives with oleic acid; (c) effect of inorganic additives with GMO. [Color figure can be viewed in the online issue, which is available at wileyonlinelibrary.com.] addition of $\mathrm{ZnO}$, clay, and hydroxyapatite alone or simultaneously with oleic acid or GMO in the range of 35.5$57.2 \%, 37.0-60.3 \%$, and $33.7-58.4 \%$, respectively. The minimum crystallinity values for oleic acid and GMO added films are $42.8 \%$ and $34.3 \%$, respectively. However, the maximum values are $46.7 \%$ and $42.8 \%$ for oleic acid and GMO, respectively. GMO lowers the crystallinity. Thus, it was possible to change the crystallinity of PCL by adding organic additives alone, inorganic additives alone, or simultaneously as well as heat treatment. The highest DOC (DSC) was obtained by using $0.1 \mathrm{wt} \%$ organoclay. Because a small amount of organoclay caused increments in the DOC, it can be said that it is the best nucleating agent. It can be seen from the results that small amounts of inorganic additives act as nucleating agents. Thus, it is possible to obtain composites with desired crystallinity values depending on the application field.

According to impressions during the stress-strain curve of the PCL film and mechanical tests, prepared composite films are highly ductile and tough. From the $B$ values, it can be concluded that organic additives improved the dispersion of inorganic additives in the polymer matrix and the interlayer of inorganic additive-polymer. In the absence of inorganic additives, Young's modulus of films decreased with $\mathrm{OA}$ and increased with GMO. The increment in the Young's modulus showed the restriction in mobility of the polymer and the increment in the hardness. The PCL composite films were flexible films with Young's modulus between 0.08 and $0.25 \mathrm{GPa}$. Their tensile strength can be changed between 6.8 and $18.5 \mathrm{MPa}$, and it is sufficient for applications that need not to carry heavy loads.

The maximum Young's modulus value $(0.25 \mathrm{GPa})$ was observed for film with $3 \% \mathrm{HA}$ and $1 \% \mathrm{OA}$. The high value of $B$ was obtained for $0.1 \%$ nanoclay-doped composite without the organic additives. The addition of organic additives to this film changed the value of $B$ to positive values, for example, to 2.3 for the addition of $3 \%$ GMO. Thus, organic additives made the interaction of the fillers and the PCL stronger.

TABLE 5. Model equations for the DOC, crystallization half-time, Avrami exponents, crystallization growth rate, Young's modulus, and tensile strength of different film samples.

\begin{tabular}{|c|c|c|c|c|c|c|}
\hline Property, Y & Sample & Variable A & Variable B & Model equation & $R^{2}$ & $F$ \\
\hline $\begin{array}{l}\text { Degree of crystallinity, } \\
\% \text { (DSC, melt) }\end{array}$ & $\mathrm{ZnO}-\mathrm{OA}$ & $\mathrm{ZnO} \mathrm{wt} \%$ & OA wt $\%$ & $Y=39.49-4.40 A-0.65 B-2.39 A B$ & 0.72 & 10.13 \\
\hline $\begin{array}{l}\text { Degree of crystallinity, } \\
\% \text { (DSC, melt) }\end{array}$ & $\mathrm{ZnO}-\mathrm{GMO}$ & $\mathrm{ZnO} \mathrm{wt} \%$ & GMO wt $\%$ & $Y=37.24-0.67 A-1.62 B+1.31 A B$ & 0.62 & 6.48 \\
\hline $\begin{array}{l}\text { Crystallization } \\
\text { half time, } t_{1 / 2}\end{array}$ & $\mathrm{ZnO}-\mathrm{GMO}$ & $\mathrm{ZnO}$ wt $\%$ & GMO wt $\%$ & $Y=10.12-1.21 A+2.35 B-2.31 B^{2}$ & 0.83 & 20.00 \\
\hline Avrami exponent, $\mathrm{n}$ & Clay-OA & Clay wt $\%$ & OA wt $\%$ & $Y=2.63+0.20 A+0.04 B-0.42 A^{2}$ & 0.75 & 12.00 \\
\hline Growth rate, $\mathrm{k}$ & $\mathrm{ZnO}-\mathrm{GMO}$ & $\mathrm{ZnO}$ wt $\%$ & GMO wt $\%$ & $Y=\left(3.33+1.38 A-5.53 B-3.07 A B+6.03 B^{2}\right) \times 10^{3}$ & 0.81 & 12.05 \\
\hline Young's modulus, Gpa & $\mathrm{ZnO}-\mathrm{OA}$ & Degree of crystallinity & $\mathrm{ZnO}$ wt $\%$ & $Y=0.11+0.01 A-0.002 B-0.02 A^{2}$ & 0.60 & 6.01 \\
\hline Young's modulus, Gpa & Clay-GMO & Degree of crystallinity & Clay wt $\%$ & $Y=0.12-0.03 A-0.01 B-0.05 A B-0.03 A^{2}$ & 0.73 & 7.29 \\
\hline Tensile strength, Mpa & HA-GMO & Degree of cystallinity & HA wt $\%$ & $Y=8.84-2.24 A-1.29 B+3.03 A^{2}$ & 0.62 & 6.46 \\
\hline
\end{tabular}


The obtained composite films are new materials that have high tensile strength and elongation at break. In this study, PCL composite materials produced as containing $\mathrm{HA}$ and OA can be used in tissue engineering as biomaterials and materials containing $\mathrm{ZnO}$ or organoclay can be used in the packaging industry.

Model equations that are statistically significant were obtained for the crystallinity, crystallization half-time, Avrami exponent, Young's modulus, and tensile strength as a function of concentration of additives. It can be concluded that the weight percentage of organic and inorganic additives have an effect on the crystallinity, and crystallization kinetics parameters have an effect on the PCL composites. For the mechanical properties of the composites, not only the concentration of additives, but also the crystallinity of the samples was found to be effective. Thus, the composition of PCL films, which have a desired DOC and mechanical properties, can be calculated by using these models. Hence, PCL films that have desired properties can be obtained by changing the type and amount of additives used.

\section{ACKNOWLEDGMENT}

This work was supported by The Scientific and Technological Research Council of Turkey (TUBITAK-110M157).

\section{REFERENCES}

1. M.A. Woodruff and D.W. Hutmacher, Prog. Polym. Sci., 35, 1217 (2010).

2. T.C. Chung and D. Rhubright, Macromolecules, 27, 1313 (1994).

3. G. Seretoudi, D. Bikiaris, and C. Panayiotou, Polymer, 43, 5405 (2002).

4. S.C. Tjong, Y. Xu, and Y.Z. Meng, Polymer, 40, 3703 (1999).

5. V. Bugatti, U. Costantino, G. Gorrasi, M. Nocchetti, L. Tammaro, and V. Vittoria, J. Eur. Polym. J., 46, 418 (2010).

6. A.L. Oliveira, S.A. Costa, R.A. Sousa, and R.L. Reis, Acta Biomater., 5, 1626 (2009).
7. D. Homminga, B. Goderis, I. Dolbnya, and G. Groeninckx, Polymer, 47, 1620 (2006).

8. K. Fukushima, C. Abbate, D. Tabuani, M. Gennari, P. Rizzarelli, and G. Camino, J. Mater. Sci. Eng. C, 30, 566 (2010).

9. L.N. Ludueña, A. Vazquez, and V.A. Alvarez, J. Appl. Polym. Sci., 109, 3148 (2008).

10. M.E.F. César, P.D.S.C. Mariani, L.H. Innocentini-Mei, and E.J.B.N. Cardoso, Polym. Test., 28, 680 (2009).

11. D.S. Rosa, C.G.F. Guedes, and F. Casarin, Polym. Bull., 54, 321 (2005).

12. H.-W. Kim, J. Biomed. Mater. Res. A, 83A, 169 (2007).

13. J.R. Olson, U.S. Patent No: 56102141997.

14. B. Alp and S. Cesur, J. Appl. Polym. Sci., 130, 1259 (2013).

15. H. Bittiger and R.H. Marchessault, Acta Cryst., B26, 112 119 (1923).

16. I.-K. Yang and C.Y. Liu, J. Polym. Sci., Pol. Phys., 48, 1777 (2010).

17. G. Zhu, Q. Xu, R. Qin, H. Yan, and G. Liang, Radiat. Phys. Chem., 74, 42 (2005).

18. B. Lepoittevin, M. Devalckenaere, N. Pantoustier, M. Alexandre, D. Kubies, C. Calberg, R. Jerome, and P. Dubois, Polymer, 43, 4017 (2002).

19. Y.T. Shieh, J.G. Lai, W.L. Tang, C.H. Yang, and T.L. Wang, J. Supercrit. Fluids, 49, 385 (2009).

20. S.C. Joseph, H.K.V. Prashanth, N.K. Rastogi, A.R. Indiramma, Y.S. Reddy, and K.S.M.S. Raghavarao, Food Bioprocess Technol., 4, 1179 (2009).

21. K.H. Janeschitz, Crystallization Modalities in Polymer Melt Processing: Fundamental Aspects of Structure Formation, Springer Wien Press, Germany (2009).

22. P.U. Dhanvijay and V.V. Shertukde, Polym.-Plast. Technol. Eng., 50, 1289 (2011).

23. V. Ratta, Crystallization, Morphology, Thermal Stability and Adhesive Properties of Novel High Performance Semicrystalline Polyimides, PhD Thesis, Virginia Polytechnic Institute (1999).

24. E. Di Maio, S. Iannace, L. Sorrentino, and L. Nicolais, Polymer, 45, 8893 (2004).

25. D. Metin, F. Tihminlioğlu, D. Balköse, and S. Ülkü, Compos. Part A-Appl. S., 35, 23 (2004). 